\title{
The Zoospore of Allomyces
}

\author{
By M. S. FULLER AND L. W. OLSON \\ Department of Botany, University of Georgia, \\ Athens, Georgia 30601, U.S.A.
}

(Accepted for publication 23 March 1971)

\begin{abstract}
SUMMARY
The arrangement of cellular organelles within the zoospores of Allomyces macrogynus and $A$. neo-moniliformis was found to be very similar to that observed in the zoospores of Monoblepharella (Monoblepharidales). Principal among these differences are the presence in Allomyces of a distinct nuclear cap, a set of 27 microtubules, a nucleus adjacent to the kinetosome, and the side body which includes the here-named Stüben bodies. Certain previous observations, including the reported absence of microtubules, of the ultrastructure of the zoospore of Allomyces have been corrected or amended.
\end{abstract}

\section{INTRODUCTION}

The striking morphological features of the thallus and the zoospores of Allomyces have fascinated mycologists ever since the first member of this genus was described by Butler (I9II). Barrett (I9I2) described the nuclear cap of the zoospores of Allomyces and noted that the cap-like structure located in the anterior portion of the zoospores was, although connected to the nucleus, a separate structure from the latter, posteriorly located organelle. The distinctness of the nucleus and nuclear cap was confirmed by Kniep (1929) and Hatch (1935).

The structure, chemical composition, and function of the nuclear cap in the Blastocladiales remained a perplexing question for many years. The nuclear cap described by Barrett (I9I2) was termed the 'food body' by him. The nuclear cap or 'food-body' of Barrett was considered a sex determinant by Hatch (1935). Both Debaisieux (1920) and Hatch (1935) concluded that this structure was derived from a fusion of mitochondria. From the work of Lovett (1963) the structure and chemical composition of the nuclear cap of one member of the Blastocladiales, Blastocladiella emersonii, has been determined. In the continuing work of Dr Lovett and others (Lovett, 1968; Schmoyer \& Lovett, 1969) the function of the nuclear cap is being revealed.

Light microscopists noted that in addition to the nucleus, nucleolus, and nuclear cap of the zoospores of Allomyces, a variety of other organelles were present. Teter (1944) noted the presence of the 'side-body' in the zoospores of Allomyces. This organelle had originally been described by Stüben (1939) and termed the seitenkörper in the zoospores of Blastocladiella.

Cotner (1930 $a, b)$ demonstrated that the zoospores of Allomyces are uniflagellate, and Kniep (1929) noted that bi- or triflagellate swarmers were the result of incomplete cleavage of the sporangial cytoplasm and that multiflagellate swarmers contained corresponding numbers of nuclei and nuclear caps. The whiplash types of flagellation of the zoospores of Allomyces was described by Couch (I94I) on the basis of light-microscope observations and confirmed by Manton, Clarke, Greenwood \& Flint (1952) in one of the earliest studies employing the electron microscope in an investigation of biological material. 
The morphology of certain aspects of zoospore formation was described by Ritchie (1947) from light-microscope observations, and by Renaud \& Swift (1964) and Moore (I968) with the use of the electron microscope. Hill (1969) has presented a description of the ultrastructure of the zoospore of Allomyces; Fuller \& Calhoun (1968) included observations on the motile cells of Allomyces in another context.

Although there has been little work done on the structure of the zoospores of Allomyces, this cannot be said of Allomyces generic relative, Blastocladiella. Cantino \& Horenstein (1956), Lovett (1963), Fuller (I966), Reichle \& Fuller (1967), Cantino, Truesdell \& Shaw (I968), Lessie \& Lovett (I968), Shaw \& Cantino (I969), Cantino \& Truesdell (1970) and Truesdell \& Cantino (1970) have presented an exhaustive, if not always consistent, description of the zoospores of Blastocladiella. The ultrastructure of the zoospores of Monoblepharella, a member of the third order of the Chytridiomycetes, the Monoblepharidales, has been described by Fuller (1966) and Fuller \& Reichle (I968).

It is the authors' intention to present a description of the ultrastructure of the zoospore of Allomyces, to correct certain previously published descriptions of the ultrastructure of the zoospores of Allomyces, and to compare and contrast the ultrastructure of the zoospores of Allomyces with the zoospores of Blastocladiella (Blastocladiales) and Monoblepharella (Monoblepharidales) to the extent that our present knowledge of the zoospores of these organisms will allow.

\section{METHODS}

The cultures of Allomyces macrogynus and A. neo-moniliformis used in this study were most generously provided by Professor R. Emerson of the Department of Botany, University of California, Berkeley, and are designated respectively as cultures 3-35 and BURMA IB in his collection. Stock cultures were maintained in test-tube culture slants on half-strength Emerson's YpSs medium (Difco). Zoosporangium discharge and subsequent release of A. macrogynus zoospores were induced by the method of Dill \& Fuller (I97I). Zoospores of $A$. neo-moniliformis were produced following the cultural procedures described by Olson \& Fuller (1971).

Zoospore suspensions were mixed with an equal volume of purified $2 \%$ glutaraldehyde (pH 6.8 to $7 \cdot 0$ ), in Machlis's dilute salt solution (DS) (Dill \& Fuller, 1971), thus giving a final fixative concentration of $I \%$. The zoospores were fixed for 15 to $25 \mathrm{~min}$. at room temperature and then centrifuged from the fixative solution; washed three times, Io min. for each wash, in Machlis's DS at room temperature; postfixed in $\mathrm{I} \% \mathrm{OsO}_{4}$ in $\mathrm{DS}$ for $20 \mathrm{~min}$. at room temperature; and, following osmification, the pellet was washed three times in DS, Io min. for each wash. Dehydration, infiltration, polymerization, sectioning, and staining are according to Fuller \& Calhoun (I968).

\section{RESULTS}

Plate I, fig. I and 2 illustrate the arrangement of the cellular organelles within the zoospores of Allomyces macrogynus as seen with the light and electron microscopes. In the lightmicroscopic view of a slightly flattened $A$. macrogynus zoospore (PI. I, fig. I) we have indicated the main classes of cellular organelles which are visible. Correspondingly, in Pl. I, fig. 2, an electron microscopic view, we have again noted these structures. In addition to the nucleus, nucleolus, nuclear cap, basal mitochondrion, and side body noted by earlier light microscopists, there are a variety of complex structures which may be seen when the zoospores of Allomyces are examined with the electron microscope. 
EXPLANATION OF PLATES

Abbreviations: BM, backing membrane; L, lipid; M, mitochondrion; MT, microtubule; N, nucleus; NC, nuclear cap; NO, nucleolus; SB, Stüben body; SBC, side-body complex.

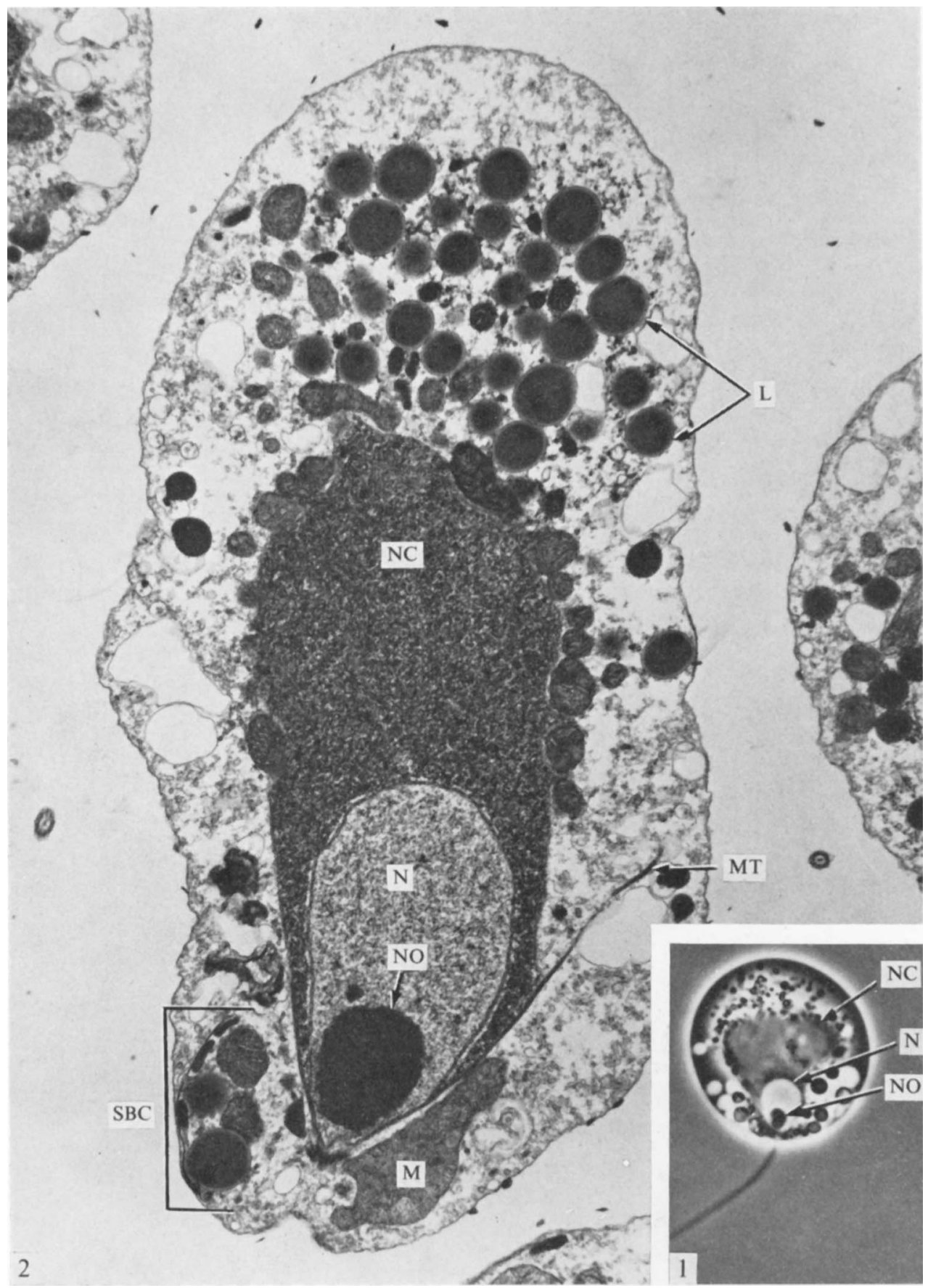

Plate I

Fig. I. Phase-contrast view of an Allomyces macrogynus zoospore. $\times 1500$.

Fig. 2. Electron microscope view of an A. macrogynus zoospore in longitudinal section. $\times$ Io,000. 

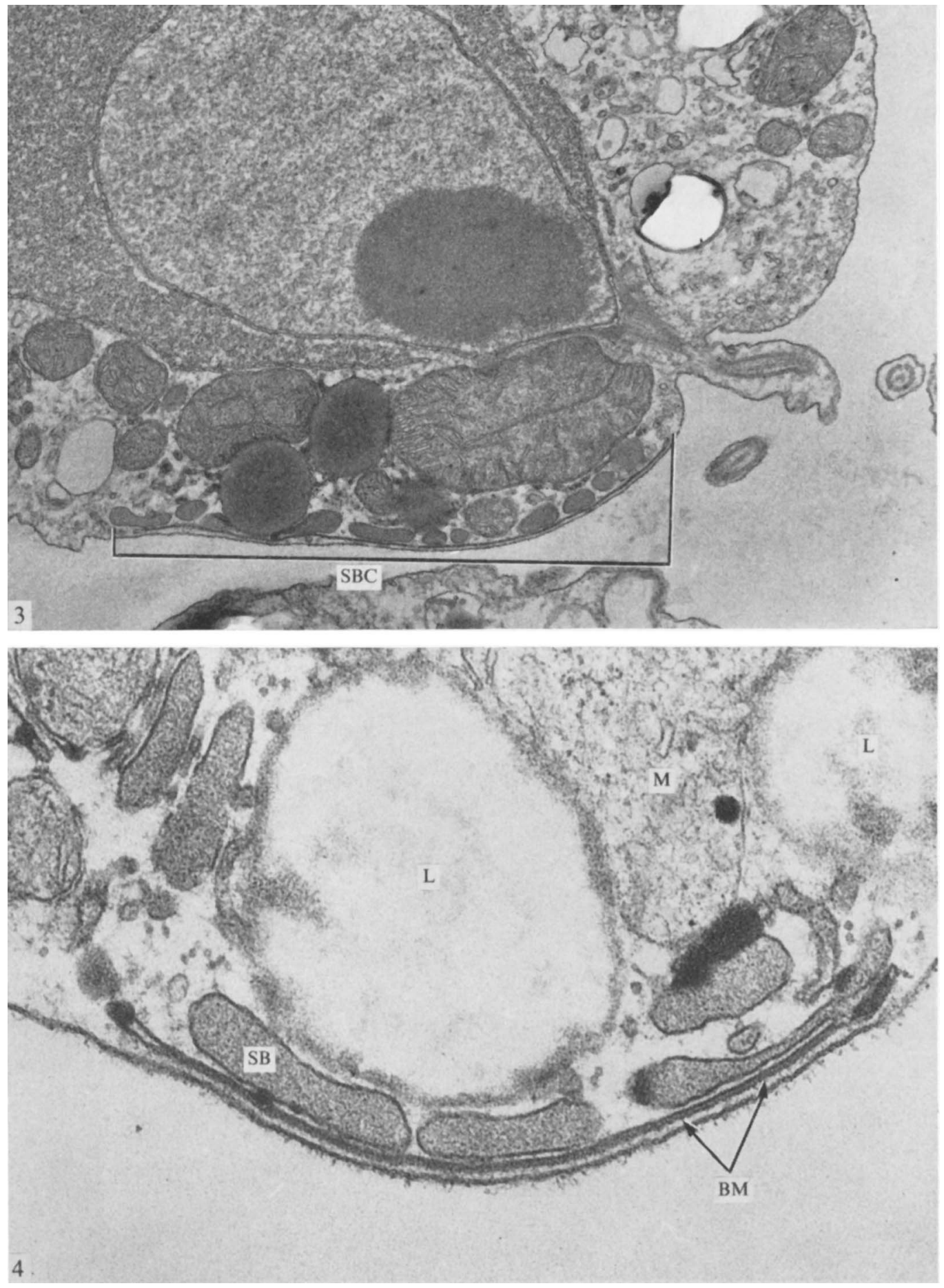

Plate 2

Fig. 3. Electron-microscope view of the posterior portion of the Allomyces macrogynus zoospore and illustrating the various components of the side-body complex. $\times 21,000$.

Fig. 4. Enlarged view of the side-body complex in A.neo-moniliformis. Note that the membrane of the Stüben body on the right is continuous with the backing membrane. $\times 29,400$. 
The seitenkörper of Stüben (1939) or side body of Teter (1944) is composed of more than one entity. The complex nature of this structure is illustrated in PI. 2, 3 and 4. Here it can be seen to be composed of two closely appressed membranes narrowly separated by an electronopaque material. These membranes subtend numerous electron-opaque, membrane-bound bodies, lipid bodies and a portion of the basal mitochondrion. The seitenkörper, with its varied components, including the portion of the large basal mitochondrion, forms a concave structure.

The origin of the double sheets of membrane at the outer limits of the side-body is in doubt at the present time. After extensive observations of sections through this membranous structure we have failed to find any connexions to the outer membrane surrounding the nucleus and nuclear cap, a possible point of origin; serial sections might reveal such a connexion. Fuller (unpublished observations) has observed that during spore development in Allomyces neo-moniliformis these double membranes first appear at the outer side of a lipid body close to the nucleus. In addition to the lipid bodies (based upon their osmophilic nature and physical appearance) which are included in the side-body (Pl. I, fig. 2; Pl. 2, fig. 3, 4), there are also electron-opaque, membrane-bound, and apparently non-lipid containing entities which Lessie \& Lovett (1968) have termed 'side-body' granules. Because we find similar bodies in all phases of the life-cycle of Allomyces and in the zoospores and sporangia (unpublished observations) of four species of Phlyctochytrium (Chytridiales), we believe that a more general name is in order and will call these structures Stüben bodies until more is known of their composition and function. In the zoospores of Allomyces the Stüben bodies are primarily located within the side-body complex, although they may assume a random location throughout the posterior portion of the Allomyces zoospore. There is a suggestion in Pl. 2, fig. 4 that the Stüben bodies may arise from, or be continuous with, the backing membrane (Pl. 2, fig. 4). The multiplicity of terms which have been used to describe the structures comprising the seitenkörper will be considered in the discussion.

The zoospore of Allomyces contains many mitochondria, including a single large basal mitochondrion and numerous smaller mitochondria which are generally located along the membrane of the nuclear cap in the anterior portion of the cell (Pl. I, Fig. 2). The mitochondria which are located on the nuclear cap occupy indentations in the nuclear cap. From extensive observations of the shape of the basal mitochondrion we have concluded that it is cupped around approximately two thirds of the posterior portion of the nucleus. The basal mitochondrion partially encloses the flagellum, kinetosome and associated structures (Pl. 2, fig. 3). This structure of the basal mitochondrion would explain why, in perfectly longitudinal sections of the zoospore, a portion of the basal mitochondrion is apparently missing from one side of the flagellum-kinetosome complex. The side-body complex has never been observed opposite the open portion of the cupped mitochondrion, but is instead adjacent to the outer portion of the basal mitochondrion (Pl. 2, Fig. 3).

The flagellum of the Allomyces zoospore has the typical nine-plus-two arrangement of microtubules which has been observed in a variety of plant, animal and other fungal cells. The flagellum intergrades with the functional kinetosome of the zoospores. Adjacent to the functional kinetosome is the non-functional kinetosome (Pl. 3, fig. 5) which Olson \& Fuller (1968) called the vestigial kinetosome. The functional and vestigial kinetosomes have a typical kinetosome structure, i.e. they are composed of nine sets of triplet microtubules. Surrounding the functional and vestigial kinetosomes is an aggregation of electron-opaque material which Fuller \& Calhoun (1968) suggested might be an 'organizing centre' for polymerizing microtubules.

Subtending the vestigial kinetosome is a pair of membranes much like a portion of endo- 
plasmic reticulum ( $\mathrm{Pl}$. 3, fig. 5). The significance of the consistent appearance of these membranes next to the vestigial kinetosome of Allomyces neo-moniliformis (Pl. 3, fig. 5) and A. macrogynus (Pl. 2, fig. 3) is not known.

Plate 3, fig. 5, Pl. 5, fig. 6, 7 illustrate portions of the striated rootlet of the Allomyces flagellum. In face view (Pl. 4, fig. 7) the rootlet is ribbon-shaped and occupies the area between the kinetosome and the basal mitochondrion. The three-dimensional structure of the

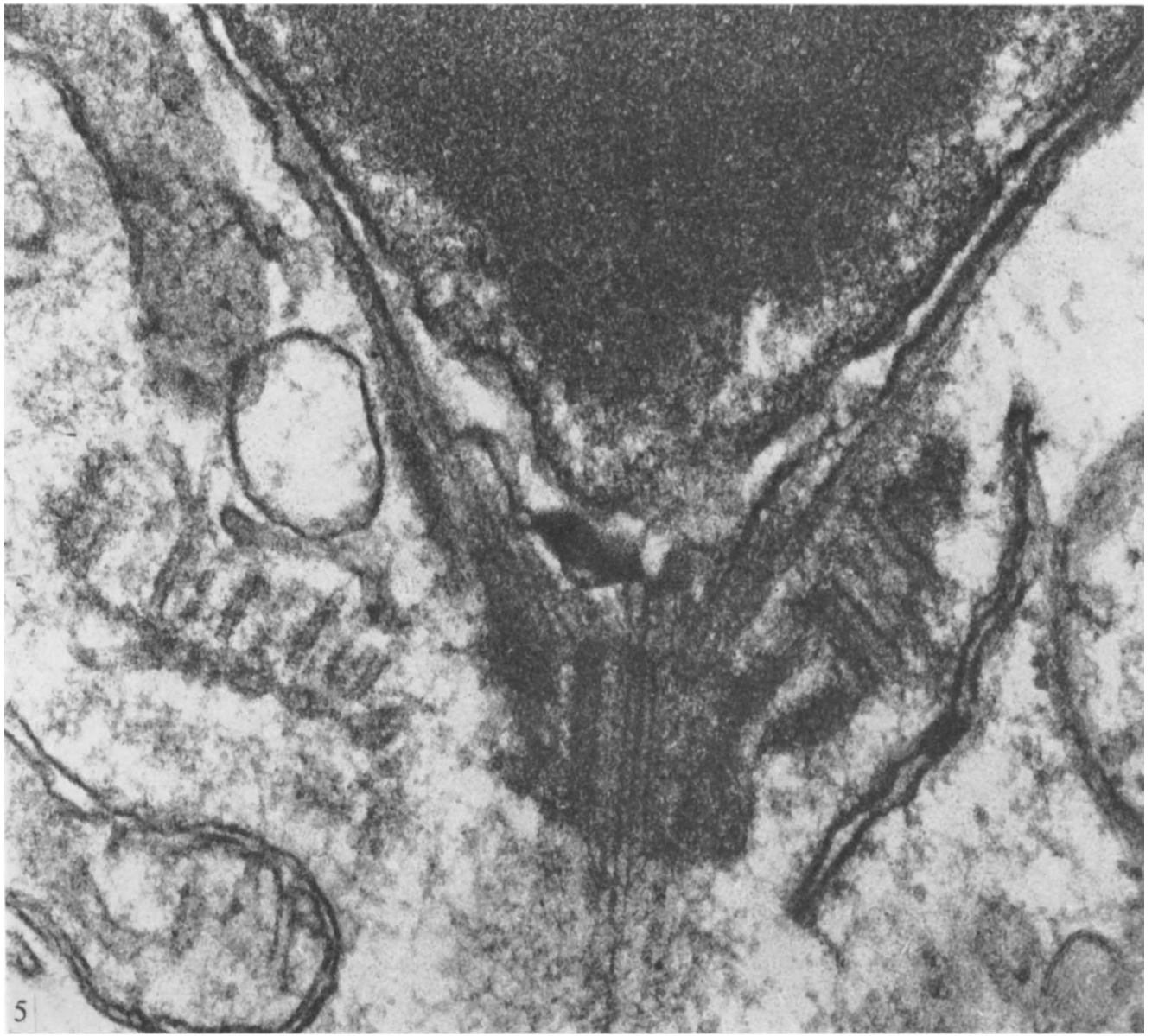

Plate 3

Fig. 5. Longitudinal section of the Allomyces neo-moniliformis zoospore. Microtubules diverge from the proximal end of the functional kinetosome. $\times$ I I 2,200.

rootlet is not clear from sections presently available. However, as seen to the left of the kinetosome in Pl. 3, fig. 5 and in Pl. 4, fig. 6 and 7, one component of the rootlet is tubular in nature. These tubules are approximately $16 \mathrm{~nm}$. in diameter, in contrast to microtubules, which are approximately $25 \mathrm{~nm}$. in diameter. Plate 4 , fig. 6 shows that there is also a fibrillar component of the rootlet which traverses the region between the kinetosome and the mitochondrion.

Surrounding the nuclear cap of the Allomyces zoospore are two membranes which are 

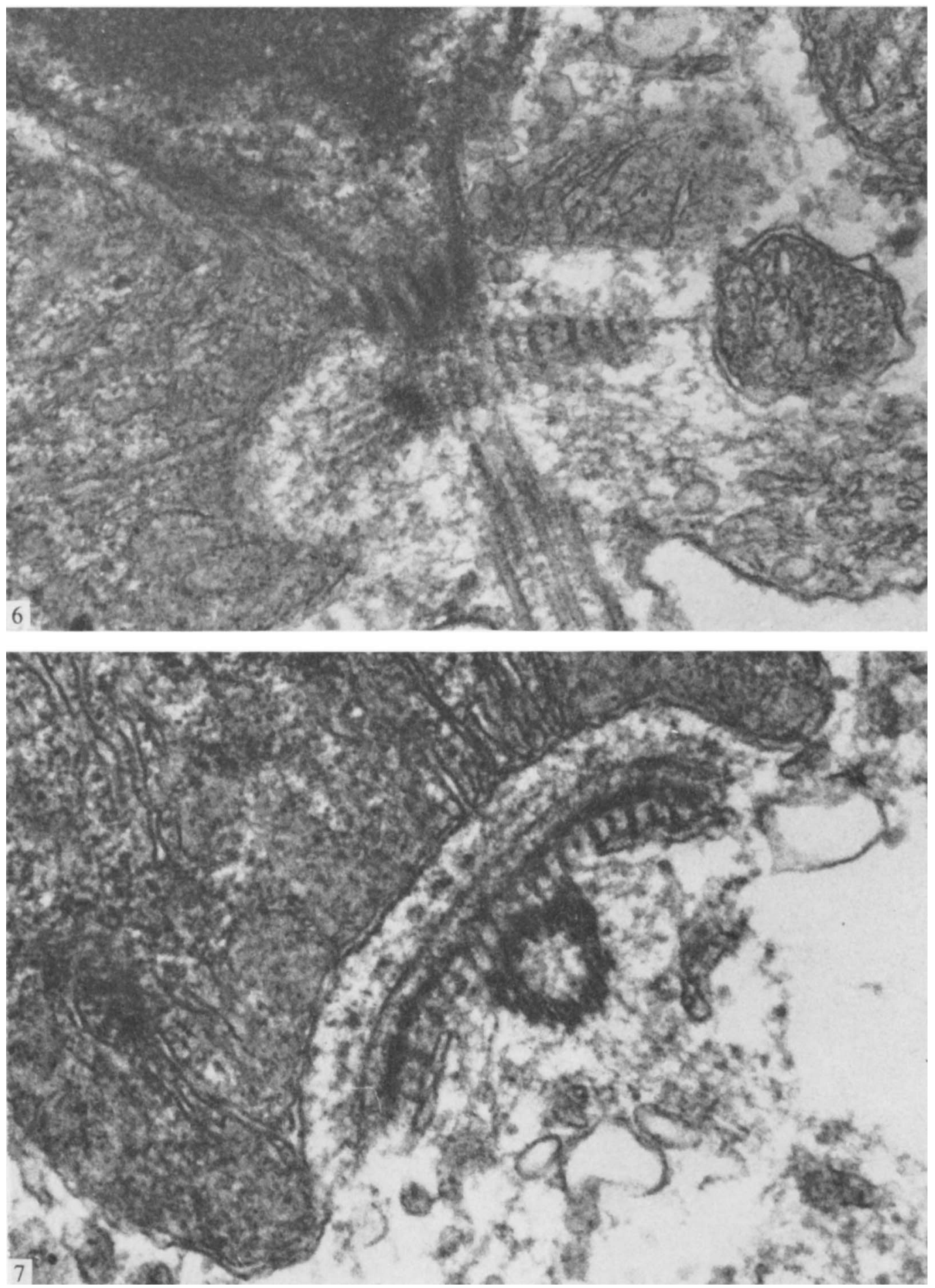

Plate 4

Fig. 6. Longitudinal view of the rootlet in Allomyces macrogynus. $\times 80,000$.

Fig. 7. Cross-section of the rootlet in A. macrogynus. $\times 80,000$. 

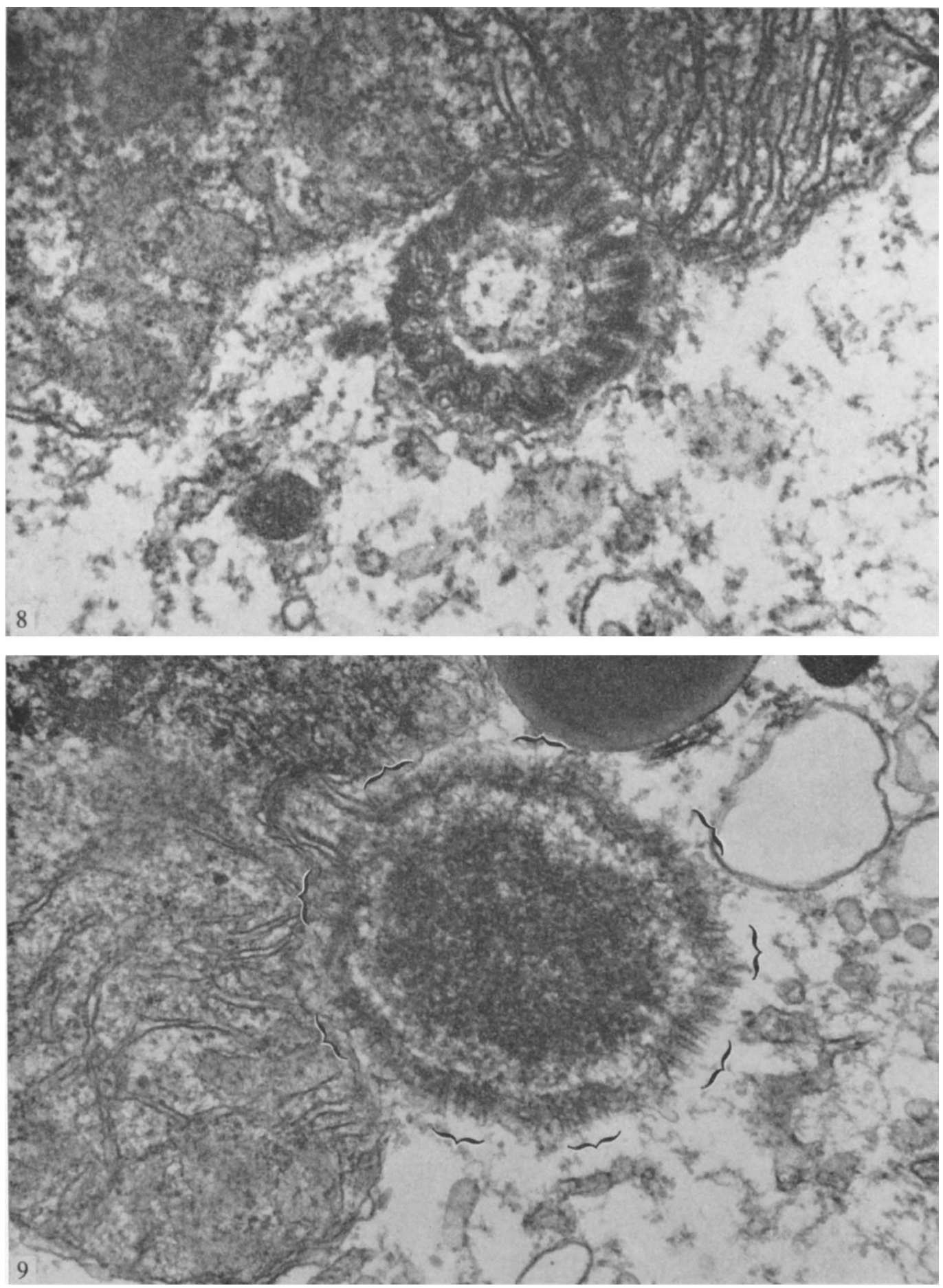

Plate 5

Fig. 8, 9. Progressively more distal views of the microtubule complex surrounding the nucleus and nuclear cap in Allomyces macrogymus. Note the nine sets of microtubule triplets (fig. 9) and the projection of the nucleus into the basal mitochondrion. $\times 90,000$ and $\times 67,500$. 
perforated at intervals by pores which generally resemble those observed in the membrane system which surrounds the nucleus (Pl. 2, fig. 3). Although the membranes which surround the nuclear cap appear to be derived from the outer membrane surrounding the nucleus, there are points where the membranes of the nuclear cap are not continuous with those of the nuclear envelope. The basal mitochondrion is not surrounded by a membrane system. Around the striated rootlet, within the basal mitochondrion, small, discrete vesicles are present (Pl. 3, fig. 5; Pl. 4, fig. 7). The absence of any vesicles around the striated rootlet shown in Pl. 4, fig. 6 would appear to suggest that if a membrane system does surround the striated rootlet it is highly fragmented and not well organized.

A group of converging microtubules is located at the proximal end of the functional kinetosome (Pl. 3, fig. 5). The microtubules flare out from the proximal end of the functional kinetosome and are closely appressed to the posterior portions of the nucleus and more anteriorly located nuclear cap. Cross-sections through an area just proximal to the functional kinetosome and through a portion of the nucleus and nucleolus are shown in Pl. 5, fig. 8 and 9. In Pl. 5, fig. 9 one can see the highly ordered nature of this array of microtubules. Twenty-seven microtubules flare out from the proximal end of the functional kinetosome in nine sets of triplets (P1. 5, fig. 9) as noted by Fuller \& Calhoun (1968) for a variety of zoospores of the Blastocladiales. Whether or not this array of microtubules actually connects to the microtubules of the functional kinetosome is still uncertain (see Pl. 3, fig. 5). The nine sets of triplet microtubules which girdle the nucleus and nuclear cap extend into the anterior portion of the zoospore beyond the nuclear cap. The consistently elongated shape of the swimming zoospores of Allomyces and the rather cone-like arrangement of the nuclear cap and nucleus may be the result of this girdling complex of microtubules.

A projection of the nucleus between two groups of triplet microtubules into an invagination of the basal mitochondrion is shown in Pl. 5, fig. 9. The nature or function of this projection from the nucleus into the basal mitochondrion is unknown, although it is a consistent feature of the motile cells of the Blastocladiales which have been studied thus far.

In addition to the spherical lipid bodies which form a part of the seitenkörper complex, numerous lipid bodies are located in the anterior portion of the zoospore (Pl. I, fig. 2). Also located in the anterior portion of the zoospore are numerous mitochondria and membrane enclosed vesicles (Pl. I, fig. 2).

Rough endoplasmic reticulum was absent from the zoospores of Allomyces which were motile at the time of fixation. The cytoplasmic ribosomes of the motile zoospore are enclosed within the nuclear cap and are not found in the cytoplasm of the zoospore. A rapid breakdown of the nuclear cap and subsequent dispersal of the ribosomes is observed upon zoospore encystment.

\section{DISCUSSION}

As described above, the seitenkörper complex, or side-body, is composed of several elements: the closely appressed sheets of membrane, Stüben bodies, lipid bodies and a portion of the basal mitochondrion. Cantino et al. (1968) have used the term 'lipid sac' to denote the aggregation of structures (two closely appressed membranes, lipid bodies and Stüben bodies) which are observed adjacent to a portion of the basal mitochondrion in the zoospores of Blastocladiella emersonii. Lessie \& Lovett (1968) have used the term 'side-body granules' to designate the membrane-bound vesicles that are filled with an electron-opaque material and located in the side-body complex. We use the term Stüben bodies to refer to similar structures found in the zoospores of Allomyces.

Reichle \& Fuller (1967) noted the presence of two types of granules in the side-body 
complex of the zoospores of Blastocladiella emersonii, one of these being electron-transparent while the other was membrane-bound and electron-dense. The identification of the membrane-bound, electron-dense granules as lipid granules was incorrect and they correspond to the 'side-body granules' described by Lessie \& Lovett (1968). The electron-transparent granules of Reichle \& Fuller (1967) appear to be the lipid granules from which the lipid was removed during the acetone dehydration of the material. Cantino \& Truesdell (1970) have termed the 'side-body granules' of Lessie \& Lovett (I968) in Blastocladiella emersonii the 'side-body matrix'. They have produced evidence with serial sections of the side-body complex in that organism that almost certainly shows the side-body granules to be interconnected to form a matrix. We do not have such evidence in Allomyces, and, as noted earlier, our evidence suggests that some of the membrane-bound granules are discrete and derived from the backing membrane.

The terms 'lipid sac' (Cantino et al. 1968), 'side-body granules' (Lessie \& Lovett, I968) and 'side-body matrix' (Cantino \& Truesdell, 1970), although descriptive, we believe should not be used in describing similar structures in the zoospores of Allomyces. The term lipid sac denotes an enclosing structure which is not observed in Allomyces and suggests that this structure only encloses lipoidal material or is made of lipid. In respect to the latter point, lipid is present but it is not the only entity present. With regard to the ultrastructure of Allomyces we consider the term side-body complex to denote sufficiently the entities which are present. The terms 'side-body granules' (Lessie \& Lovett, I968) or 'side-body matrix' (Cantino \& Truesdell, 1970) designate the membrane-bound vesicles filled with electron-opaque material observed in the side-body complex of Allomyces. However, these terms do not accurately describe similar structures when they are observed in other portions of the zoospores of Allomyces and do not correctly reflect the nature of these bodies when they are observed in the thallus or sporangium of Allomyces or the zoospores and sporangium of Phlyctochytrium.

The term Stüben body has been adopted, in preference to the terms side-body granules or side-body matrix, by the authors because of its less definite connotations as to location or chemical properties. Priority of description would identify these structures as being an integral part of the seitenkörper complex or side body originally noted by Stüben (1939). The term Stüben bodies would also be of use in denoting these structures in other portions of the life-cycle of Allomyces, Blastocladiella or other organisms. When the chemical composition of these structures becomes known perhaps a more definite term which reflects the chemical nature and function of these structures can be substituted for Stüben bodies.

Hill (1969) reported that the ribosomes of the motile cells of Allomyces are not always confined by the membrane sheath of the nuclear cap but may be located in unbounded aggregates in the spore cytoplasm or between layers of rough endoplasmic reticulum. In our observations of the zoospores of the same species of Allomyces as studied by Hill (I969), we have found the exact opposite to be true. As in the zoospores of Blastocladiella, the ribosomes are contained within the bounds of the enclosing membranes of the nuclear cap, and rough endoplasmic reticulum is totally lacking during the motile period of the Allomyces zoospores. We have noted, however, that those Allomyces zoospores which have been centrifuged prior to fixation, or those spores which have withdrawn their flagellum, do have ribosomes present in the cytoplasm of the zoospore. The centrifugation step used by Hill (I969) prior to fixation could have produced sufficient spore disorientation or induced zoospore encystment and thus account for the unusual morphology of the Allomyces zoospore which he noted. Hill (1969) also reports the absence of striations (microtubules) within the secondary or vestigial kinetosome, termed centriole by Hill, of the zoospores of 
Allomyces macrogynus. The microtubular nature of the vestigial kinetosome of Allomyces is clearly shown in P1. 4, fig. 5. It would appear that the 'centriole' observed by Hill (I969) was either a non-median or oblique section of this structure (see fig. 5), with the material he described being the electron-opaque material which surrounds the vestigial kinetosome, or, and more likely, the 'centriole' of his fig. Io is a section of a poorly preserved rootlet and, therefore, comparable to our Pl. 4, fig. 6.

Hill (1969) noted that the zoospores of Allomyces macrogynus lacked internal microtubules such as described by Fuller (1966) or Fuller \& Reichle (1968) for the zoospores of Blastocladiella emersonii. However, the presence of a complex arrangement of microtubules in the zoospores of Allomyces was noted earlier by Fuller \& Calhoun (I968) and is clearly shown in Pl. 3, fig. 5 to Pl. 5, fig. 8, described here. The apparent lack of microtubules within the zoospores of Allomyces macrogynus studied by Hill (1969) may have been due to the long duration of fixation ( $40 \mathrm{~min}$., in $\mathrm{I} \% \mathrm{OsO}_{4}$ ) which he used. But the tubular structures he described as running on either side of the nuclear cap and stated 'may function as microtubules in giving internal stability to the cell...' are clearly the equivalent of the microtubules described by Fuller \& Calhoun (1968).

The presence of the concentric granule noted by Hill (1969) in the zoospore of Allomyces macrogynus is a relatively rare occurrence and should not be considered to be a regular component of the zoospore of Allomyces. The concentric granule is much more frequently observed in other stages of the life-cycle of Allomyces (Skucas, 1968) with the exception of the gametes, as noted by Blondell \& Turian (1960).

The similarity of the zoospores of Allomyces and Blastocladiella is revealed by a comparison of the micrographs of the zoospore of Allomyces presented here with previous descriptions of the zoospore of Blastocladiella (Fuller, 1966; Reichle \& Fuller, 1967; Lessie \& Lovett, 1968; Cantino et al. 1968; Cantino, 1969; Cantino \& Mack, 1969). The arrangement of the nuclear cap, nucleus, microtubules complex, seitenkörper complex, basal mitochondrion and lipid drops are similar. Gamma bodies, such as those seen in the zoospores of Blastocladiella emersonii (Cantino \& Horenstein, 1956; Cantino, 1969; Cantino \& Mack, I969; Truesdell \& Cantino, 1970) have not been observed in the zoospores of Allomyces. The zoospores of Blastocladiella emersonii have been found to contain a single basal mitochondrion, similar in some respects to the basal mitochondrion of Allomyces, but the zoospores of Blastocladiella lack the secondary mitochondria which are present in the zoospore of Allomyces.

The striking morphological similarity of the zoospores of Allomyces and Blastocladiella is not observed in comparisons of the zoospores of Monoblepharella, (Monoblepharidales) (Fuller \& Reichle, I968). The nuclear cap of Monoblepharella, although similar in structure to the nuclear cap observed in Allomyces, differs significantly in its position, orientation, complete absence of a confining nuclear cap membrane, and the presence of sheets of membranous material which traverse the nuclear cap. The nucleus and ribosome-containing region of the zoospores of Monoblepharella are not located adjacent to the functional kinetosome as observed in the zoospores of Allomyces, but are located more centrally within the zoospore. The striated rootlet of the zoospores of Monoblepharella is circular, surrounding the functional kinetosome, while the rootlet of Allomyces is a single bar-like structure adjacent to the functional kinetosome. There is no basal mitochondrian or blastocladialian seitenkörper complex in the zoospore of Monoblepharella. Flaring out from the circular rootlet of Monoblepharella is a system of microtubules which extends forward in the zoospore, but unlike the microtubule complex of Allomyces these microtubules pass through the nuclear cap. A posteriorly positioned cristate structure designated as the 
'rumposome' by Fuller (1966) is present in the zoospores of Monoblepharella. Similar structures have been observed in the chytrids (Chytridiales) Nowakowskiella (Chambers, Markus \& Willoughby, 1967) and Chytridium (Koch, 1956) but have not been observed in the zoospores of Allomyces or Blastocladiella (Blastocladiales).

The research reported here was supported by an NSF grant GB-4529 to M.S.F. and an NSF Predoctoral Fellowship to L.W.O. We wish to thank Dr F. Perkins of the Virginia Institute of Marine Science, Gloucester Point, Virginia, for the generous use of his Hitachi HU I I B electron microscope.

\section{REFERENCES}

BARrett, J. T. (19I2). The development of Blastocladia strangulata n.sp. Botanical Gazette 54, 353-37I.

Blondell, B. \& Turian, G. (1960). Relation between basophilia and fine structure of cytoplasm in the fungus Allomyces macrogynus Em. Journal of Biochemical Cytology 7, I27-I 34.

Butler, E. J. (1911). On Allomyces, a new aquatic fungus. Annals of Botany 25, 1023-1035.

CANTINo, E. C. \& Hornstein, E. A. (1956). Gamma and the cytoplasmic control of differentiation in Blastocladiella. Mycologia 48, 443-446.

Cantino, E. C., Truesdell, L. C. \& Shaw, D. S. (1968). Life history of the motile spore of Blastocladiella emersonii: a study in cell differentiation. Journal of Elisha Mitchell Scientific Society 94, 125-146.

CANTINo, E. C. \& MACK, J. B. (1969). Form and function in the zoospore of Blastocladiella emersonii. I. The gamma particle and satellite ribosome package. Nova Hedwigia 18, I $15-148$.

Cantino, E. C. (1969). The gamma particle, satellite ribosome package and spheroidal mitochondria in the zoospore of Blastocladiella emersonii. Phytopathology 59, 107I-1076.

Cantino, E. C. \& Truesdell, L. C. (1970). Organization and fine structure of the side-body and its lipid sac in the zoospore of Blastocladiella emersonii. Mycologia 62, 548-567.

Chambers, T. C., Markus, K. \& Willoughby, L. G. (1967). The fine structure of the mature zoosporangium of Nowakowskiella profusa. Journal of General Microbiology 46, I35-14I.

COTNER, F. B. (I930a). Cytological study of the zoospores of Blastocladia. Botanical Gazette 89, 295-309.

COTNER, F. B. $(1940 \mathrm{~b})$. The development of the zoospores in the oomycetes at optimum temperatures and the cytology of their active stages. American Journal of Botany 17, 5 I I-546.

Couch, J. N. (I94I). The structure and action of the cilia in some aquatic Phycomycetes. American Journal of Botany 28, 704-7I 3.

DebaisieuX, P. (1920). Coelomycidium simulii, nov. gen., nov.spec., et remarques sur l'amœbidium des Laves de Simulim. La Cellule 30, 249-276.

Dill, B. \& Fuller, M. S. (1971). Amino acid immobilization of motile fungal cells. Archiv für Mikrobiologie. (In the Press.)

Fuller, M. S. (1966). Structure of the uniflagellate zoospores of aquatic Phycomycetes. Colston Papers 18, 67-82.

Fuller, M. S. \& Calmoun, S. A. (1968). Microtubule-kinetosome relationships in the motile cells of the Blastocladiales. Zeitschrift für Zellforschung und Mikroskopische Anatomie 87, 526-533.

Fuller, M. S. \& Reichle, R. (1968). The fine structure of Monoblepharella sp. zoospores. Canadian Journal of Botany 46, 279-283.

Hatch, W. R. (1935). Gametogenesis in Allomyces arbuscula. Annals of Botany 49, 623-649.

HILL, E. P. (1959). The fine structure of the zoospores and cysts of Allomyces macrogynus. Journal of General Microbiology 56, 125.

KNIEP, H. (1929). Allomyces javanicus n.sp. ein anisogamer Phycomycet mit Planogameten. Bericht der deutschen botanischen Gesellschaft 4I, 199-2 I 2.

KосH, W. J. (1956). Studies of the motile cells of chytrids. I. Electron microscope observations of the flagellum, blepharoplast and rhizoplast. American Journal of Botany 43, 8I I-8I9.

LESSIE, P. E. \& LoVETT, J. S. (1968). Ultrastructural changes during sporangium formation and zoospore differentiation in Blastocladiella emersonii. American Journal of Botany 55, 220-236.

LOVETT, J. S. (1963). Chemical and physical characterization of 'nuclear caps' isolated from Blastocladiella zoospores. Journal of Bacteriology 85, I $235-\mathrm{I} 246$.

LOVETT, J. S. (1968). Reactivation of ribonucleic acid and protein synthesis in zoospores of Blastocladiella and the role of the ribosomal nuclear cap. Journal of Bacteriology 96, 962-969. 
Manton, I., Clarke, B., Greenwood, A. D. \& Fuint, E. A. (1952). Further observations on the structure of plant cilia by a combination of visual and electron microscopy. Journal of Experimental Botany 3, 204-215.

MOORE, R. T. (1968). Fine structure of Mycota. XIII. Zoospore and nuclear cap formation in Allomyces. Journal of the Elisha Mitchell Scientific Society 84, I47-165.

OLSON, L. W. \& FULLER, M. S. (1968). Ultrastructural evidence for the biflagellate origin of the uniflagellate fungal zoospore. Archiv für Mikrobiologie 62, 237-250.

Olson, L. W. \& Fuller, M. S. (197I). Leucine-lysine synchronization of Allomyces germlings. Archiv für Mikrobiologie. (In the Press.)

REICHLE, R. E. \& FULLER, M. S. (1967). The fine structure of Blastocladiella emersonii zoospores. American Journal of Botany 54, 8I-92.

ReNaUd, F. L. \& SwIFT, H. (1964). The development of basal bodies and flagella in Allomyces arbusculus. Journal of Cell Biology 23, 339-354.

RITCHIE, D. (1947). The formation and structure of the zoospore in Allomyces. Journal of the Elisha Mitchell Scientific Society 63, 168-206.

SCHMOYeR, I. R. \& LOVETT, L. S. (1969). Regulation of protein synthesis in zoospores of Blastocladiella. Journal of Bacteriology 100, 854-864.

Shaw, D. S. \& CANTINO, E. C. (1969). An albino mutant of Blastocladiella emersonii. Comparative studies of zoospore behaviour and fine structure. Journal of General Microbiology 59, 369-382.

SkUCAS, G. P. (1968). Changes in wall and internal structure of Allomyces-resistant sporangia during germination. American Journal of Botany 55, 291-295.

STÜBEN, H. (1939). Ubber Entwicklungsgeschichte und Ernährungsphysiologie eines neuen niederen Phycomyceten mit Generationswechsel. Planta 30, 353-383.

TETER, H. E. (1944). Isogamous sexuality in a new strain of Allomyces. Mycologia 36, 194-210.

Truesdell, L. C. \& CANTINo, E. C. (1970). Decay of gamma particles in germinating zoospores of Blastocladiella emersonii. Archiv für Mikrobiologie 70, 378-392. 